\title{
Assessing countermeasures during a hepatitis A virus outbreak among men who have sex with men
}

\author{
Ryohei Saito', Akifumi Imamura ${ }^{2}$ and Hiroshi Nishiura ${ }^{1,3^{*}}$ (1)
}

\begin{abstract}
Background: A hepatitis A epidemic occurred among men who have sex with men (MSM) in Japan in 2017-2018. In this study, we employ a parsimonious mathematical model to epidemiologically investigate the dynamics of infection, aiming to evaluate the effectiveness of campaign-based interventions among MSM to raise awareness of the situation.

Methods: A mathematical model describing a mixture of human-to-human transmission and environmental transmission was fitted to surveillance data. Taking seasonally varying environmental transmission into account, we estimated the reproduction number of hepatitis A virus during the course of epidemic, and, especially, the abrupt decline in this reproduction number following campaign-based interventions.

Results: The reproduction number prior to the countermeasures ranged from 2.6 to 3.1 and then began to decrease following campaign-based interventions. After the first countermeasure, the reproduction number decreased, but the epidemic remained supercritical (i.e., $R_{t}>1$ ). The value of $R_{t}$ dropped well below one following the second countermeasure, which used web articles to widely disseminate information about the epidemic risk.

Conclusions: Although the effective reproduction number, $R_{t}$ changes because of both intrinsic and extrinsic factors, the timing of the examined countermeasures against hepatitis A in the MSM population was consistent with the abrupt declines observed in $R_{t}$. Even without vaccination, the epidemic was brought under control, and risky behaviors may have been changed by the increase in situation awareness reached through web articles.
\end{abstract}

Keywords: Intervention, Awareness, Epidemic, Mathematical model, Sexually transmitted infection

\section{Background}

Hepatitis A, an acute viral infectious disease, is a type of hepatitis that frequently involves long-lasting fever, nausea, vomiting, diarrhea, abdominal pain, and strong fatigue, with or without jaundice [1], although the infection is sometimes asymptomatic. The disease tends to be more serious in older people than in younger people, and most children aged under 6 years

*Correspondence: nishiura.hiroshi.5r@kyoto-u.ac.jp

${ }^{3}$ Kyoto University School of Public Health, Yoshidakonoecho, Sakyo-ku, Kyoto-shi, Kyoto 606-8503, Japan

Full list of author information is available at the end of the article are asymptomatic [2]. The disease is caused by hepatitis A virus (HAV), which is transmitted via the fecaloral route and also by eating contaminated food [2]. In particular, poorly or insufficiently cooked shellfish often acts as the source of infection [3]. HAV is widely prevalent in the environment, and it is able to survive a variety of food-production procedures [4]. The transmission involves seasonal variation, with the majority of infections occurring in the spring and summer [5]. Although hepatitis A has become rarer in industrialized countries, it still spreads sporadically, and the virus is globally prevalent, with periodic outbreaks. The ecological dynamics remain largely unknown but are believed original author(s) and the source, provide a link to the Creative Commons licence, and indicate if changes were made. The images or other third party material in this article are included in the article's Creative Commons licence, unless indicated otherwise in a credit line to the material. If material is not included in the article's Creative Commons licence and your intended use is not permitted by statutory regulation or exceeds the permitted use, you will need to obtain permission directly from the copyright holder. To view a copy of this licence, visit http://creativecommons.org/licenses/by/4.0/. The Creative Commons Public Domain Dedication waiver (http://creativeco mmons.org/publicdomain/zero/1.0/) applies to the data made available in this article, unless otherwise stated in a credit line to the data. 
to be regulated by the concentration and habitat of shellfish [6]. In Asia, a large outbreak of HAV occurred in Shanghai in 1988, involving 300,000 infections [7]. People who recover from natural infection with HAV develop life-long immunity [8], and a safe and effective (inactivated or live-attenuated) vaccine is available [9]. The main public health efforts to control the infection are supplying safe water and food, improving hygiene, encouraging handwashing, and immunizing those who are susceptible [5]. In general, the incubation period ranges from 14 to 28 days [10]. Serological diagnosis is made by confirming elevated serum immunoglobulin $M$ antibodies [2]. There is no specific treatment for hepatitis A, and only supportive care is routinely offered [2, 4].

Infection with HAV can occur by direct mucous-to-mucous contact, especially among men who have sex with men (MSM) [2]. MSM sex tourism across national borders is recognized as an important avenue of introducing new outbreaks [11], and many outbreaks of hepatitis A occur among MSM. The timing of hepatitis A outbreaks has involved a certain time lag as they have moved across the globe, with a surge of patients occurring among MSM from 2015 to 2017 in Taiwan [12-14], from 2016 to 2017 in Europe [15-29], from 2016 to 2018 in the United States [30, 31], and in 2018 in Japan [11, 32]. Spatial spread (e.g., from Taiwan and Europe to Japan) has been partly demonstrated via genome sequencing [11, 32]. In 2018, Japan experienced a large outbreak in which the majority of cases were young men (Fig. 1A and B). Recent sporadic cases have occurred among MSM in previous decades [33], and it was not difficult to anticipate another outbreak in 2018. A particularly substantial increase in disease incidence was seen in Tokyo (Fig. 1C) and Osaka [32]. Fortunately, the outbreak was brought under control in about 6 months (Fig. 1A). The confirmed cases in Japan from 2006-19 were dominated by men, indicating that the transmission was highly heterogeneous, fueled by the population of MSM, and women was perhaps dead-end host or acquired infection from environment (Fig. 1D).

Hepatitis A is a notifiable disease; thus, Japan collects data on counts of all diagnosed cases [34], and we were able to use the publicly available data to assess interventions from 2017 to 2018. In this study, we employed a parsimonious mathematical model to epidemiologically investigate the dynamics of infection. The purpose of the study was to evaluate the effectiveness of interventions by quantitatively assessing the impact of campaigns that were implemented among MSM in terms of reducing the incidence of hepatitis A infection. We also examined the transmission dynamics in Japan, referring to published evidence on the transmission dynamics of HAV in the past [35-43].

\section{Methods}

\section{Epidemiological data}

In the Japanese Law of Infection Control, hepatitis A is a class 4 notifiable disease and must be reported within 24 hours of confirmatory diagnosis. Confirmatory diagnosis is made by polymerase chain reaction or serologically by elevated immunoglobulin $\mathrm{M}$ titer. After anonymizing the data, the National Institute of Infectious Diseases reports a weekly record of the frequency of cases [34]. During the course of the outbreak of HAV from 2017 to 2018, various preventive campaigns were conducted among MSM. In particular, special efforts were made from February 13 to May 5, 2018 (see Table 1 for a detailed chronology). For instance, special pamphlets were widely distributed on February 29, and an online article warning readers about the outbreak that was published on March 30 was accessed over 120,000 times. Because these campaigns were the most likely interventions to have increased recognition of the outbreak, we labeled February 29 as $t_{1}$ and March 30 as $t_{2}$ for use in our modeling analysis. That is, the most strengthened effort to let people recognize the outbreak was made with 1000 pamphlets on $t_{1}$ (February 29), and the costly approach via web article was conducted on $t_{2}$ (March 30).

\section{Mathematical model}

HAV is transmitted via environmental and human-tohuman routes. To account for this fact, we assumed that the observed epidemic curve can be decomposed into two distinct types of transmission (i.e., those infected via the environmental route and those infected via human-to-human transmission; Fig. 2). We thus described the mixture of these two mechanisms and fitted our model to the data. Environmental transmission is governed by a hazard that varies seasonally, with a summer peak. The other type, humanto-human transmission, is caused by sexual contact among men, and a renewal equation was used to describe the dynamics. Modeling the incidence of infection, the epidemic curve, described using the date of illness onset, was calculated as the convolution of the incidence and the incubation period.

Seasonal variation in the environmental transmission was modeled using the trigonometric function for periodic changes, which we assumed to be a good approximation. This model is described as follows:

$$
a(t)=a_{0}+\sum_{k=1}^{n} a_{k} \sin \left(\frac{2 \pi k t}{52}+b_{k}\right),
$$

where $a(t)$ is the number of newly infected cases caused by environmental transmission at calendar time $t$ (weeks), $n$ is the number of terms in the 

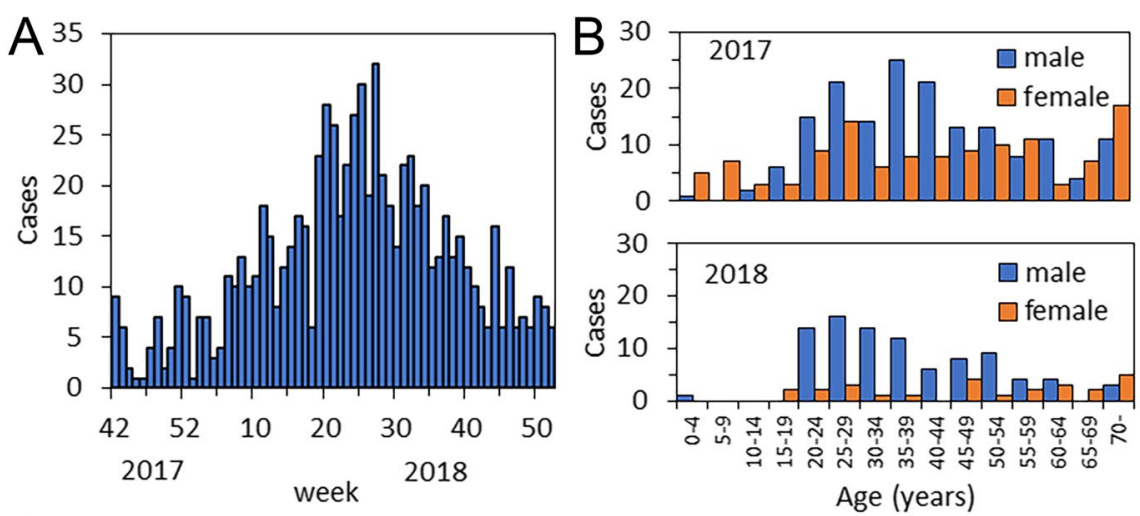

\section{C}

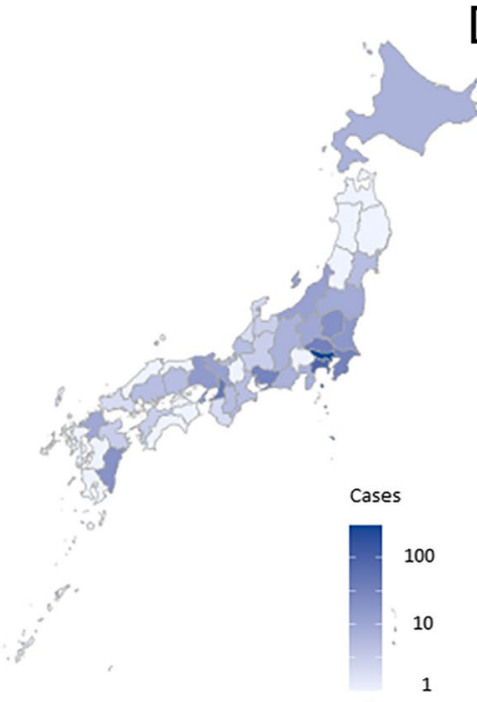

$D_{1000}$
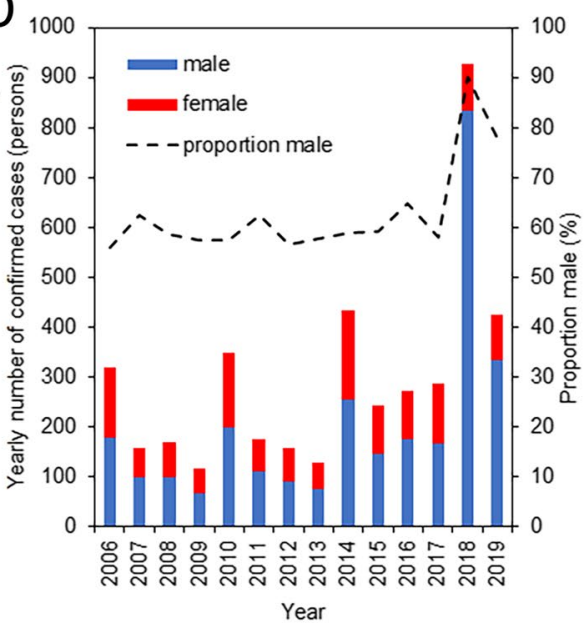

Fig. 1 Epidemic curve of hepatitis A in Japan in 2018 by week, age, and sex distribution. A Temporal distribution of the incidence (serologically diagnosed cases) from 2017 to 2018. B Age distribution of serologically diagnosed cases. The data from 2017 are based on whole-year notifications, but the 2018 data were gathered only up to July 26th. In 2017, the age distribution was fairly flat for women and peaked at $35-39$ years for men, and the male-to-female ratio was not particularly high. In contrast, most cases in 2018 occurred in young men aged $20-55$ years. $\mathbf{C}$ Spatial distribution of serologically diagnosed cases from 2017 to 2018. Many cases were diagnosed in the Kanto region, which includes the Tokyo metropolitan area, followed by Osaka Prefecture, the third largest prefecture in western Japan. D Sex distribution of confirmed cases from $2006-19$. Proportion male is measured on right vertical axis

trigonometric function, and $a_{0}, a_{k}$, and $b_{k}$ are the estimated parameters.

Let $j(t)$ be the number of cases newly infected via human-to-human transmission at calendar time $t$. They are produced by people infected in the past, and, on average, each primary case generated $R_{1}$ secondary cases:

$$
j(t)=R_{1} \int_{0}^{t} j(t-s) g(s) d s .
$$

Here, $g(s)$ is the discretized probability density function of the generation time, derived as
$g(s)=G(s)-G(s-1)$, where $G(s)$ is the cumulative distribution function of the generation time, assumed to be a lognormal distribution with a median of 27.5 days and a standard deviation of 4 days [10]. When the first countermeasure was implemented at time $t_{1}$, the reproduction number changed from $R_{1}$ to $R_{1} \varepsilon_{1}\left(0<\varepsilon_{1}<1\right)$. Therefore, the renewal equation also changed to

$$
j(t)=R_{1} \varepsilon_{1} \int_{0}^{t} j(t-s) g(s) d s .
$$


Table 1 Chronology of interventions against the hepatitis A virus outbreak among MSM in Japan, 2018

\begin{tabular}{|c|c|c|}
\hline Calender time & $\begin{array}{l}\text { Time } \\
\text { parameter }\end{array}$ & Events \\
\hline \multirow[t]{3}{*}{ 13-Feb-18 } & & Submission of data of pamphlet \\
\hline & & Published a web article \\
\hline & & Information via twitter \\
\hline 26-Feb-18 & & Distributed 305 posters \\
\hline 29-Feb-18 & $\mathrm{t}_{1}^{\mathrm{b}}$ & Printed and distributed 1000 pamphlets \\
\hline 9-Mar-18 & & Distributed 165 posters \\
\hline 9-Mar-18 & & Published a web article in HIV map (which is accessed by substantial number of men who have sex with men) \\
\hline 10-Mar-18 & & Distributed 20 posters \\
\hline 12-Mar-18 & & Distributed 10 posters \\
\hline 17-Mar-18 & & Put an article on a magazine \\
\hline 30-Mar-18 & $t_{2}^{c}$ & Published a web article \\
\hline 3-May-18 & & Distributed 20 pamphlets \\
\hline 5-May-18 & & $\begin{array}{l}\text { Distributed (i) } 165 \text { and (ii) } 1815 \text { pamphlets for (i) delivery health project, Shinjuku 2-chome and bar and (ii) } \\
\text { Tokyo Rainbow Pride Parade (for LGBTQ) in Yoyogi Park, respectively }\end{array}$ \\
\hline
\end{tabular}

MSM men who have sex with men

$t_{1}$ was the time at which the first campaign was implemented. $t_{2}$ was the time at which the second campaign was implemented

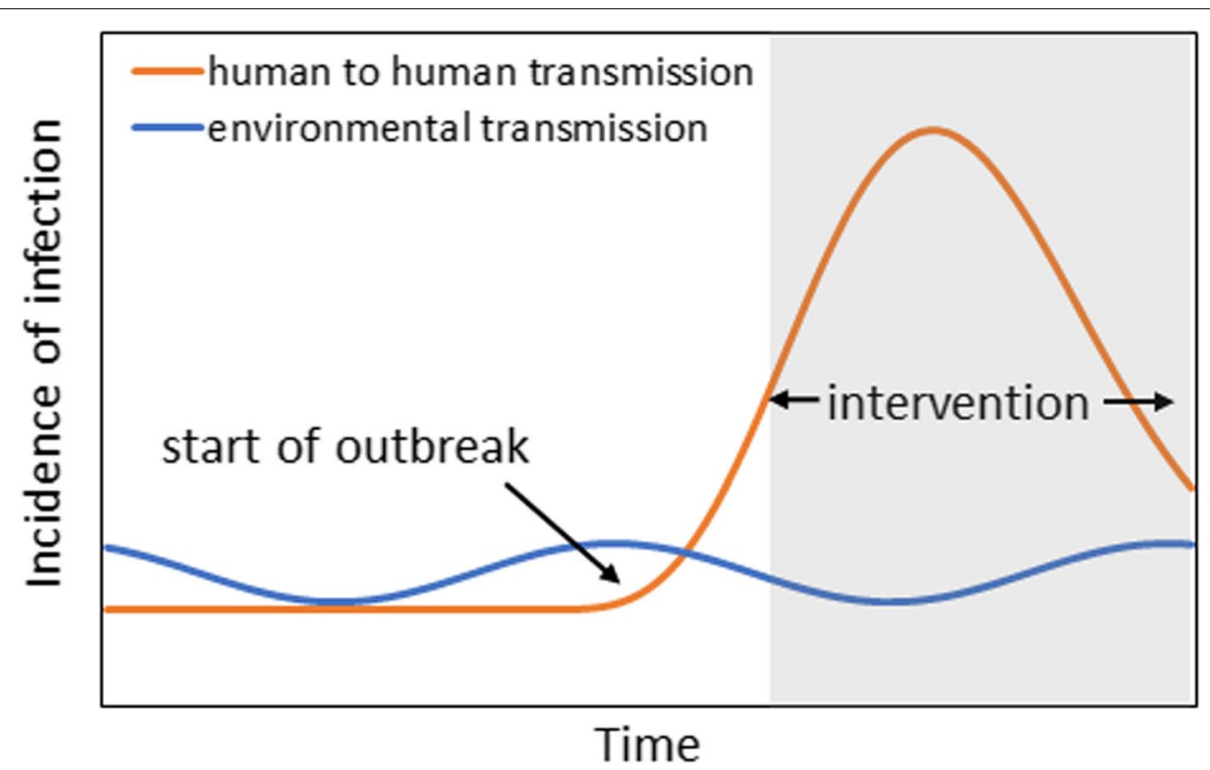

Fig. 2 Interpreting the observed patterns of the epidemic curve. We assumed that the observed epidemic curve could be decomposed into environmental transmission and human-to-human transmission. Environmental transmission, which varies seasonally, corresponds to a sine-like curve. The other curve represents human-to-human transmissions among men who have sex with men

Similarly, when the second countermeasure was conducted at time $t_{2}$, the reproduction number changed from $R_{1} \varepsilon_{1}$ to $R_{1} \varepsilon_{1} \varepsilon_{2}\left(0<\varepsilon_{2}<1\right)$. Therefore, the renewal equation changed to

$$
j(t)=R_{1} \varepsilon_{1} \varepsilon_{2} \int_{0}^{t} j(t-s) g(s) d s .
$$

Alternatively, we also examined the case in which intervention effects were time-dependent. That is, we considered $R_{1} \varepsilon_{1}^{t-t_{1}}$ rather than $R_{1} \varepsilon_{1}$ and also $R_{1} \varepsilon_{1}^{t_{2}-t_{1}} \varepsilon_{2}^{t-t_{2}}$ rather than $R_{1} \varepsilon_{1} \varepsilon_{2}$. 
Taking the sum of environmentally and human-tohuman transmitted cases $-a(t-s)$ and $j(t-s)$, respectively-and convoluting it with the incubation period, we obtained the expected number of cases with illness onset at calendar time $t, E\left[c_{t}\right]$ :

$$
E\left[c_{t}\right]=\int_{0}^{t}(j(t-s)+a(t-s)) f(s) d s .
$$

Here, $f(s)$ is the probability density function of the incubation period with a median of 28 days and a standard deviation of 9 days [10]. During the computation, we discretized the abovementioned models by week; thus, the integral $\int d s$ becomes the discrete sum $\sum$. Assuming that the observed incidence data followed a Poisson distribution, the likelihood function is

$$
L\left(t_{\theta}, R_{1}, \varepsilon_{1}, \varepsilon_{2} ; \boldsymbol{x}_{t}\right)=\Pi_{t} \frac{E\left[c_{t}\right]^{x_{t}} \exp \left(-E\left[c_{t}\right]\right)}{x_{t} !},
$$

given the observed number of cases $x_{\mathrm{t}}$ in week $t$. Here, $t_{\theta}$ is the week in which the first human-tohuman transmission took place, and we assume that there were only environmental transmissions prior to $t_{\theta}$.

Because parameters $\varepsilon_{1}$ and $\varepsilon_{2}$ can vary with the serial interval, which is assumed to be known in the present study, it is vital to examine how these parameters take on different values if the serial interval is changed. As a sensitivity analysis, we estimated these parameters by varying the ratio of the standard deviation to the mean (i.e., the coefficient of variation, CV) of the serial interval. We also considered the following alternative model as part of sensitivity analysis, accounting for potential dependence between environmental and human-to-human transmissions, i.e.,

$$
j(t)=R(t) \int_{0}^{t}(j(t-s)+a(t-s)) g(s) d s,
$$

where $R(t)$ stands for the effective reproduction number at calendar time $t$ and then,

$$
E\left[c_{t}\right]=\int_{0}^{t} j(t-s) f(s) d s .
$$

For the original model, the following model assumptions were made. First, we assumed that the generation time followed a log-normal distribution. Second, preventive campaigns were assumed to abruptly influence the infection dynamics. The third assumption was that the two interventions independently influenced the epidemic dynamics, meaning that the combined impact could be modeled as the product of $\varepsilon_{1}$ and $\varepsilon_{2}$. Fourth, the epidemic dynamics were assumed to be a simple additive function of environmental transmission and human-to-human transmission, and the former was assumed to be approximated by a periodic function. Finally, we assumed that all infectious persons were diagnosed and reported.

\section{Ethical considerations}

This study analyzed data that are publicly available. The datasets used in our study were de-identified and fully anonymized in advance. The analysis of publicly available data (Supplementary Data 1) without identity information does not require ethical approval.

\section{Results}

To quantify the seasonal model (Eq. 1), nine possible combinations were examined by varying $n$, the number of terms in the trigonometric function (0 to 2), and the length of learning data (2015-2017, 2016-2017, and 2017). Comparing Akaike information criterion (AIC) values, the minimum value was obtained when $n=1$ and learning data from either 2016-2017 or 2017 were used. Across the examined learning data periods, the minimum AIC value was observed when $n=1$; thus, we decided to adopt $n=1$ in the model combining seasonal variation in environmental transmission and human-to-human transmission in the MSM population. Figure 3A compares the predictions using 2017 as learning data with the observed data, showing that most of the observed data were contained within the $95 \%$ confidence intervals (CIs) of the predictions. The human-to-human transmission epidemic was estimated to begin in the 35th week in 2017. Quantifying the transmission dynamics, we observed that the human-to-human transmission peaked around the time when the second countermeasure was implemented (Fig. 3B).

The estimated parameters along with their 95\% CIs are summarized in Table 2. Overall, the presence of seasonality (i.e., $n=1$ or 2 ) was favored, compared with the constant baseline (i.e., $n=0$ ). The AICs using different learning data cannot be compared because of different amounts of empirical data across the time periods. While parameter values in Table 2 show those of public health interests, coefficients of trigonometric functions were also estimated, and the parameter estimates are available as Supplementary Data 2. In the following analyses, we present the results using the 2017 learning data because, although it was likely, we did not explicitly account for human-to-human transmission in the data from earlier years. The reproduction number before the interventions, $R_{1}$, was estimated to range from 2.6 to 3.1 , and $n=0$ always yielded a greater $R_{1}$ estimate compared with $n=1$ or $n=2$. The relative risk of transmission 


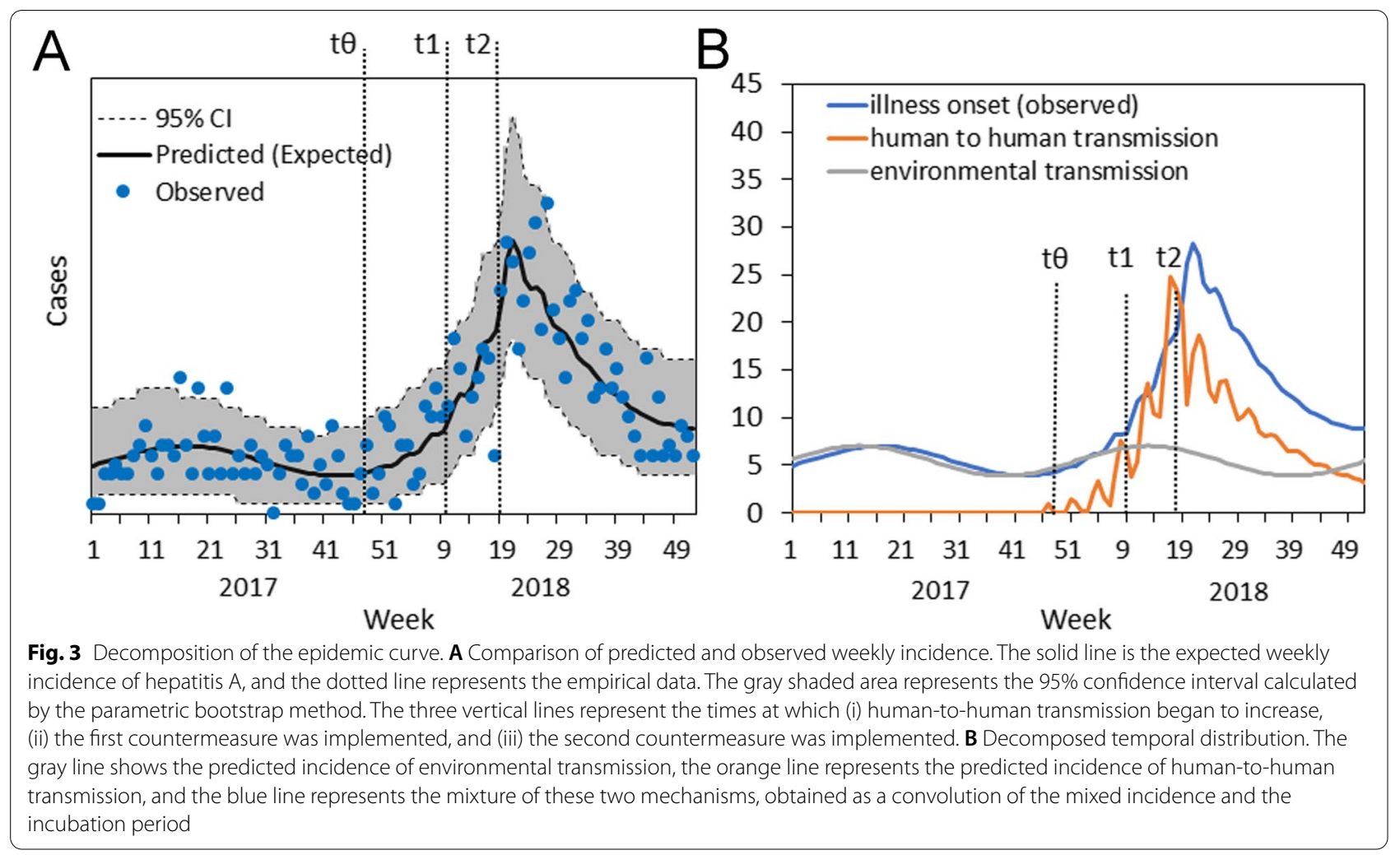

Table 2 Estimated parameters and its 95\% Cl, time of outbreak, number of parameters, and AlCa for each model assumption

\begin{tabular}{|c|c|c|c|c|c|}
\hline Model assumption & $R_{1}^{b}$ & $\varepsilon_{1}^{c}$ & $\varepsilon_{2}^{d}$ & $\begin{array}{l}\text { Number of } \\
\text { parameters }\end{array}$ & AIC \\
\hline Constant, 17 & $3.05(2.63,3.47)$ & $0.60(0.38,0.82)$ & $0.41(0.30,0.52)$ & 5 & 566.0 \\
\hline Sine curve, 17 & $2.80(2.32,3.29)$ & $0.72(0.39,1.04)$ & $0.39(0.27,0.52)$ & 7 & 554.6 \\
\hline Second-order trigonometric, 17 & $2.80(2.32,3.29)$ & $0.72(0.39,1.04)$ & $0.39(0.27,0.52)$ & 9 & 558.6 \\
\hline Constant, 16-17 & $3.07(2.66,3.49)$ & $0.59(0.37,0.80)$ & $0.42(0.30,0.53)$ & 5 & 832.8 \\
\hline Sine curve, 16-17 & $2.74(2.24,3.24)$ & $0.76(0.40,1.12)$ & $0.38(0.26,0.51)$ & 7 & 797.8 \\
\hline Second-order trigonometric, $16-17$ & $2.60(2.07,3.13)$ & $0.87(0.42,1.33)$ & $0.35(0.23,0.47)$ & 9 & 798.3 \\
\hline Constant, 15-17 & $3.13(2.71 .3 .53)$ & $0.57(0.37,0.77)$ & $0.43(0.32,0.54)$ & 5 & 1079,1 \\
\hline Sine curve, $15-17$ & $2.82(2.35,3.30)$ & $0.72(0.40,1.03)$ & $0.39(0.27,0.51)$ & 7 & 1040.4 \\
\hline Second-order trigonometric, 15-17 & $2.68(2.18,3.19)$ & $0.82(0.42,1.27)$ & $0.36(0.24,0.47)$ & 9 & 1038.0 \\
\hline
\end{tabular}

In all models, the estimated starting time of the outbreak was week 35 in 2017. Estimated values of parameters for trigonometric function are available from Supplementary Data 2

${ }^{\text {a }}$ Akaike Information Criteria

${ }^{b}$ reproductin number

c coefficient of the first measure

${ }^{d}$ coefficient of the second measure

e estimated time of invention of the first case of Hepatitis A by MSM

at the time of the first countermeasure, which involved the dissemination of pamphlets by non-governmental organizations associated with MSM, ranged from 0.59 to 0.87. Using the 2017 data with $n=1, \varepsilon_{1}$ was estimated at 0.72 (95\% CI: $0.39-1.04)$. At the time of the second countermeasure, which used online web articles, the additional relative impact was estimated to range from 0.36 to 0.43 . Using the 2017 data with $n=1, \varepsilon_{2}$ was estimated at 0.39 (95\% CI: $0.27-0.52$ ). Thus, the reproduction number was $0.72 \times 0.39=0.28$ times the baseline; 


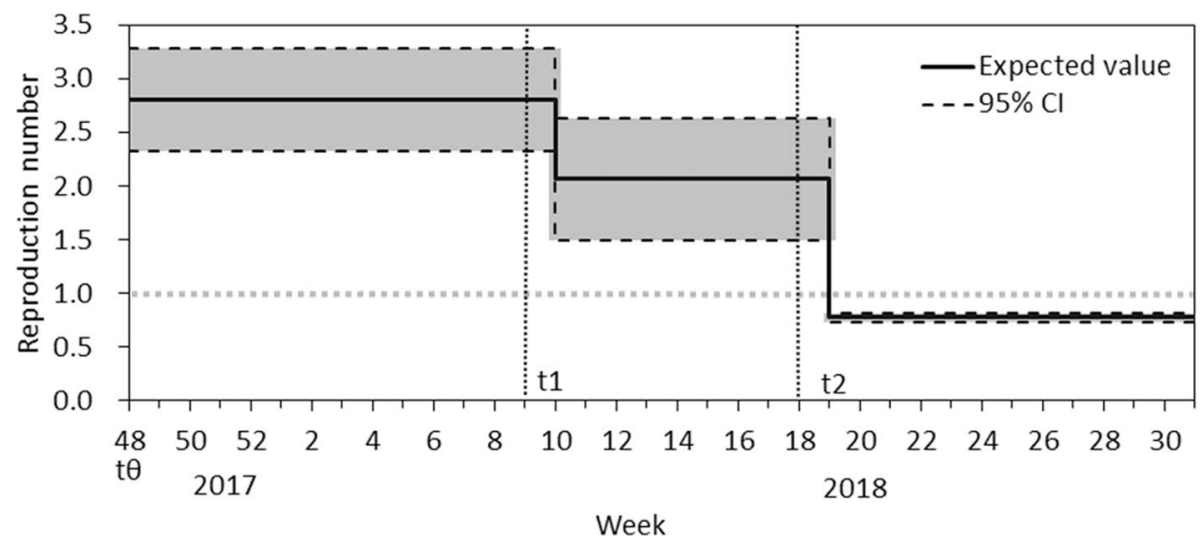

Fig. 4 Estimated effective reproduction numbers. The solid line shows the reproduction number, and the gray shaded area shows the $95 \%$ confidence interval. The reproduction number decreased following the first and second countermeasures and, notably, fell below one following the second countermeasure

accordingly, the reproduction number fell below one, and the incidence started to decline (Fig. 4). It should also be noted that the upper bound of the CI for the reproduction number fell below one following the second countermeasure.

Applying the alternative model with time-dependent effect of interventions to 2015-17 data, sine function model was best-fit, and baseline $R_{1}$ was estimated at 2.00. Parameters $\varepsilon_{1}$ and $\varepsilon_{2}$ were estimated to be 0.96 and 1.03, respectively. The AIC value of this model was 1183.6 which was greater than the original model with AIC $=1040.4$ (Table 2).

A sensitivity analysis was carried out. In particular, we examined how sensitive $\varepsilon_{1}$ and $\varepsilon_{2}$ were to variation in the $\mathrm{CV}$ of the serial interval (Fig. 5). Except for very small $\mathrm{CV}$ values, which would perhaps be unrealistic, the relative risk of transmission remained stable as $\mathrm{CV}$ varied.
Thus, the estimated impact of the examined campaigns in terms of preventing hepatitis A transmission was shown to be robust to variation in the generation time, which remained uncertain in our model. Accounting for the possible dependence between environmental and human-to-human transmissions, the alternative model yielded subcritical value of $R_{1}$, which is understandable for continued full involvement of environmentally infected individuals in the chains of transmission (but $R_{1}<1$ was unlikely if the epidemic was induced mainly by contact in the population of MSM). For instance, using the data from 2015-17 and adopting a constant baseline, $R_{1}$ was estimated at 0.83 (95\% CI: $0.51,1.14$ ). AIC values of this alternative approach was always greater than those of original model.
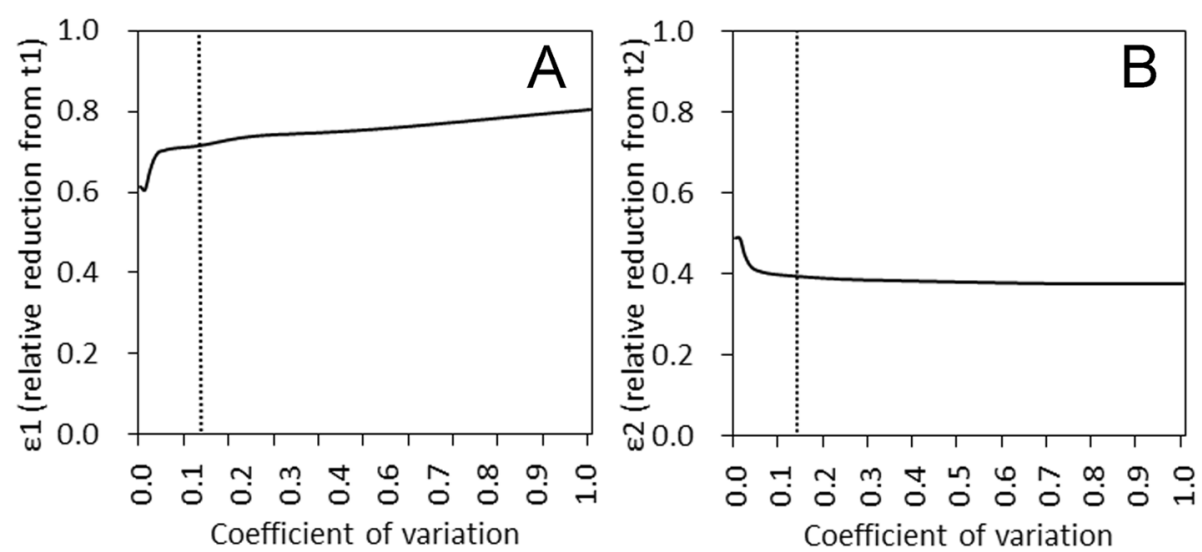

Fig. 5 Sensitivity of the relative risk of transmission to serial interval variations. We fixed the median of the serial interval at 27.5 days [10]. In this figure, we varied the variance value, calculating the coefficient of variation to vary from zero to one. The vertical line shows the point that was used in the actual estimation 


\section{Discussion}

The present study explored the epidemic of HAV that resulted in a surge of cases among adult men in 2018 in Japan [32]. During this epidemic, preventive campaigns were conducted to help avoid further transmission in the MSM population. Our study evaluated the effectiveness of these campaigns. Devising a mathematical model and estimating the parameters using surveillance data, we successfully captured the epidemic dynamics, quantifying the seasonal variation in environmental transmission. Prior to the countermeasures, the reproduction number ranged from 2.6 to 3.1 ; this value then started to decrease following the campaign-based interventions. After the first countermeasure, the reproduction number decreased, but the epidemic remained highly critical (i.e., $R_{t}>1$ ). $R_{t}$ fell well below one following the second countermeasure. Although the effective reproduction number, $R_{t}$, changes because of both intrinsic and extrinsic factors, the present study suggests that the interventions that were implemented to raise situation awareness regarding the epidemic among the MSM population were influential. In contrast to the case in Japan, vaccination was required to control recent HAV epidemics in many other countries (e.g., the United States [30, 44] and Taiwan [35]).

In this study, we have objectively shown that $R_{t}$ abruptly declined following the two examined campaign periods, although the possibility of intrinsic effects (e.g., saturation of infections because of clustering) cannot be excluded. Thus, our conclusion is conditional on the decline in $R_{t}$ being attributed to extrinsic effects. However, we do not believe that the extent of transmission showed a clear clustering pattern, and the MSM population size is substantial; thus, it is likely that behavioral changes reduced risky contact. We examined the timing of two independent campaign periods. Of the two examined campaigns, the latter intervention, which involved publishing an online article, likely had a greater impact in terms of reducing the reproduction number. Given our study results, it would be valuable to survey the MSM population to investigate which types of input and messages were influential in promoting their behavioral changes.

What must be learned from this hepatitis A outbreak is that the MSM population in Japan is continuously exposed to the chance of HAV infection and that this risk is influenced by travelers visiting Japan. In this sense, although the examined campaigns were successful and no vaccination took place in this time period, it would be valuable to consider possible preventive vaccination against HAV. Acceptance of and demand for this vaccine should be surveyed in future studies.
As an important step forward in epidemiological modeling, we have modeled empirical data on HAV infection as a mixture of a renewal process and environmental transmission. This approach did not allow us to produce a closed-form likelihood, but we have numerically minimized the likelihood, modeling the illness onset data as a convolution of infection time-based incidence data and incubation period. Without understanding the likely timing of infection, it would not have been possible to explicitly evaluate the abrupt declines in $R_{t}$. As for environmental transmission, seasonally fluctuating exposure was favored over assuming a constant hazard over time. This finding indicates the presence of seasonal variation, which may reflect exposure to seasonally varying risks (e.g., differences in eating and drinking). However, it must be noted that we assumed the absence of any outbreak among MSM during the control period; in this sense, there is room for improvement. Possible dependence between environmental and human-to-human transmissions was also examined, but AIC values of such models were greater than original models, and it was difficult to fully explain the plausibility of resulting parameters.

Several limitations must be acknowledged. First, we did not consider sexual contact or age, and future models should take these factors into account. Second, as an important direct indication of effectiveness, it would have been useful to monitor contact patterns directly. We used a step function to model $R_{t}$, potentially reflecting contact patterns over time, but observing diminishing patterns of risky contact would provide more direct evidence for the effectiveness of the public health campaigns. Third, our model relied on surveillance notification data. There could be unreported cases, although underreporting of HAV infection is unlikely to be very frequent. Fourth, our model simulated a mixture of human-to-human and environmental transmission, and having genome and travel-history data would have allowed us to further disentangle the case data in a direct manner.

Despite these limitations, we believe the present study successfully shows that the timing of countermeasures against hepatitis A in the MSM population in Japan was consistent with abrupt declines in $R_{t}$. This finding suggests that using online articles may have the potential to have widespread impact in terms of changing risky behaviors.

\section{Conclusions}

The present study explored the HAV epidemic that resulted in a surge of cases among adult men in 2018 in Japan, as well as the preventive campaigns conducted to help avoid further transmission in the MSM population. The reproduction number prior to the countermeasures ranged from 2.6 to 3.1 ; this value began to decrease following the campaign-based interventions, falling well 
below one following the second countermeasure, which used an online article. Risky behaviors may have been changed by increasing situation awareness.

\section{Abbreviations}

AIC: Akaike information criterion; Cl: confidence interval; CV: Coefficient of variation; HAV: Hepatitis A virus; MSM: Men who have sex with men.

\section{Supplementary Information}

The online version contains supplementary material available at https://doi. org/10.1186/s12976-021-00150-1.

\section{Additional file 1.}

Additional file 2.

\section{Acknowledgments}

We thank Jennifer Barrett, PhD, from Edanz (https://jp.edanz.com/ac) for editing a draft of this manuscript.

\section{Authors' contributions}

HN conceived the study. RS and HN conceptualized the study design, collected the data, formulated the mathematical models, and performed the statistical analyses. RS and HN drafted an early version of the manuscript. Al provided comments on an earlier version of the manuscript. All authors provided input on the revised manuscript and approved the final version of the manuscript.

\section{Funding}

This study was mainly supported by Health and Labor Sciences Research Grant (H29-AIDS-General-006; PI: Akifumi Imamura). HN received funding from Health and Labor Sciences Research Grants (19HB1001, 19HA1003, 20CA2024, 20HA2007 and 21HB1002), the Japan Agency for Medical Research and Development (AMED; JP19fk0108104, JP20fk0108140 and JP20fk0108535s0101), the Japan Society for the Promotion of Science (JSPS) KAKENHI (17H04701 and 21H03198), the Japan Science and Technology Agency (JST) CREST program (JPMJCR1413), and the SICORP (e-ASIA) program (JPMJSC20U3 and JPMJSC2105). The funders were not involved in the collection, analysis, or interpretation of the data, the writing of the manuscript, or the decision to submit the work for publication.

\section{Availability of data and materials}

The original data used to construct the epidemic curve are available as Supplementary Data 1.

\section{Declarations}

\section{Ethics approval and consent to participate}

This study analyzed data that are publicly available. The datasets used in our study were de-identified and fully anonymized in advance. The analysis of publicly available data without identity information does not require ethical approval.

\section{Consent for publication}

Not applicable.

\section{Competing interests}

HN is the Editor-in-Chief of Theoretical Biology and Medical Modelling. This does not alter the authors' adherence to all of the journal's policies on sharing data and materials.

\section{Author details}

${ }^{1}$ Graduate School of Medicine, Hokkaido University, Kita 15 Jo Nishi 7 Chome, Kita-ku, Sapporo-shi, Hokkaido 060-8638, Japan. ${ }^{2}$ Department of Infectious Diseases, Tokyo Metropolitan Cancer and Infectious Diseases Center Komagome Hospital, 3-18-22 Honkomagome, Bunkyo-ku, Tokyo 113-8677,
Japan. ${ }^{3}$ Kyoto University School of Public Health, Yoshidakonoecho, Sakyo-ku, Kyoto-shi, Kyoto 606-8503, Japan.

Received: 26 May 2021 Accepted: 4 October 2021

Published online: 11 October 2021

\section{References}

1. Franco E, Meleleo C, Serino L, Sorbara D, Zarattil L. Hepatitis A: epidemiology and prevention in developing countries. World J Hepatol. 2012;4:68-73.

2. Matheny SC, Kingery JE. Hepatitis A. Am Fam Physician. 2012;86:1027-34 quiz 1010-2.

3. Bellou M, Kokkinos P, Vantarakis A. Shellfish-borne viral outbreaks: a systematic review. Food Environ Virol. 2013;5:13-23.

4. World Health Organization. Hepatitis A. 2019. https://www.who.int/newsroom/fact-sheets/detail/hepatitis-a. Accessed 24 Jul 2019.

5. Fares A. Seasonality of hepatitis: a review update. J Family Med Prim Care. 2015:4:96-100.

6. Costantino A, Coppola N, Spada E, Bruni R, Taffon S, Equestre M, et al. Hepatitis A virus strains circulating during 1997-2015 in Campania, a Southern Italy region with periodic outbreaks. J Med Virol. 2017:89:1931-6.

7. Cooksley WGE. What did we learn from the Shanghai hepatitis A epidemic? Journal of Viral Hepatitis. 2000;7:1-3.

8. Bennett JE, Dolin R, Blaser MJ., editors. Mandell, Douglas, and Bennett's principles and practice of infectious diseases. 8th ed. New York: Saunders; 2015. https://www.sciencedirect.com/book/9781455748013/mande II-douglas-and-bennetts-principles-and-practice-of-infectious-diseases. Accessed 26 May 2021

9. WHO position paper on hepatitis A vaccines - June 2012. Wkly Epidemiol Rec. 2012;87:261-76.

10. Bonačić Marinović A, Swaan C, van Steenbergen J, Kretzschmar M. Quantifying reporting timeliness to improve outbreak control. Emerg Infect Dis. 2015;21:209-16.

11. Watanabe S, Morimoto N, Miura K, Takaoka Y, Nomoto H, Tsukui M, et al. Full-genome characterization of the RIVM-HAV16-090-like hepatitis A virus strains recovered from Japanese men who have sex with men, with sporadic acute hepatitis A. Hepatol Res. 2019;49:521-30.

12. Chen WC, Chiang PH, Liao YH, Huang LC, Hsieh YJ, Chiu CM, et al. Outbreak of hepatitis A virus infection in Taiwan, June 2015 to September 2017. Euro Surveill. 2019:24. https://doi.org/10.2807/1560-7917.es.2019. 24.14.1800133.

13. Chen NY, Liu ZH, Shie SS, Chen TH, Wu TS. Clinical characteristics of acute hepatitis A outbreak in Taiwan, 2015-2016: observations from a tertiary medical center. BMC Infect Dis. 2017;17:441.

14. Cheng CY, Wu HH, Zou H, Lo YC. Epidemiological characteristics and associated factors of acute hepatitis A outbreak among HIV-coinfected men who have sex with men in Taiwan, June 2015-December 2016. J Viral Hepat. 2018;25:1208-15.

15. Mauro MV, Greco F, Tenuta R, Apuzzo G, Costantino A, Bruni R, et al. Hepatitis A outbreak affecting men who have sex with men (MSM) in South Italy. New Microbiol. 2019;42:181-3.

16. Ruscher C, Werber D, Thoulass J, Zimmermann R, Eckardt M, Winter C, et al. Dating apps and websites as tools to reach anonymous sexual contacts during an outbreak of hepatitis A among men who have sex with men, Berlin, 2017. Euro Surveill. 2019;24:1800460.

17. Alberts CJ, Boyd A, Bruisten SM, Heijman T, Hogewoning A, Rooijen MV, et al. Hepatitis A incidence, seroprevalence, and vaccination decision among MSM in Amsterdam, the Netherlands. Vaccine. 2019:37:2849-56.

18. Bradley-Stewart A, Smith-Palmer A, Hawkins G, Gunson R. Hepatitis A-2017 an unusual year in Scotland. J Clin Virol. 2019;115:1-4.

19. Marosevic D, Belting A, Schönberger K, Carl A, Wenzel JJ, Brey R. Hepatitis A outbreak in the general population due to a MSM-associated HAV genotype linked to a food handler, November 2017-February 2018. Germany. Food Environ Virol. 2019;11:149-56.

20. Sabrià A, Gregori J, Garcia-Cehic D, Guix S, Pumarola T, Manzanares-Laya S, et al. Evidence for positive selection of hepatitis A virus antigenic variants 
in vaccinated men-having-sex-with men patients: implications for immunization policies. EBioMedicine. 2019;39:348-57.

21. Petersen J, Freedman J, Ford L, Gawthrop M, Simons H, Edelstein M, et al. Changes to country-specific hepatitis A travel vaccination recommendation for UK travellers in 2017-responding to a vaccine shortage in the national context. Public Health. 2019;168:150-6.

22. Ndumbi P, Freidl GS, Williams CJ, Mårdh O, Varela C, Avellón A, et al. Hepatitis A outbreak disproportionately affecting men who have sex with men (MSM) in the European Union and European Economic Area, June 2016 to May 2017. Euro Surveill. 2018;23:1700641.

23. Boucher A, Meybeck A, Alidjinou K, Huleux T, Viget N, Baclet V, et al. Clinical and virological features of acute hepatitis A during an ongoing outbreak among men who have sex with men in the North of France. Sex Transm Infect. 2019;95:75-7.

24. Comelli A, Izzo I, Casari S, Spinetti A, Bergamasco A, Castelli F. Hepatitis A outbreak in men who have sex with men (MSM) in Brescia (Northern Italy), July 2016-July 2017. Infez Med. 2018;26:46-51.

25. Beebeejaun K, Degala S, Balogun K, Simms I, Woodhall SC, Heinsbroek $E$, et al. Outbreak of hepatitis A associated with men who have sex with men (MSM), England, July 2016 to January 2017. Euro Surveill. 2017:22:30454.

26. Freidl GS, Sonder GJ, Bovée LP, Friesema IH, van Rijckevorsel GG, Ruijs WL, et al. Hepatitis A outbreak among men who have sex with men (MSM) predominantly linked with the EuroPride, the Netherlands, July 2016 to February 2017. Euro Surveill. 2017;22:30468.

27. Gozlan Y, Bar-Or I, Rakovsky A, Savion M, Amitai Z, Sheffer R, et al. Ongoing hepatitis A among men who have sex with men (MSM) linked to outbreaks in Europe in Tel Aviv area, Israel, December 2016 - June 2017. Euro Surveill. 2017;22:30575.

28. Rodríguez-Tajes S, Perpiñán E, Caballol B, Lens S, Mariño Z, Costa J, et al. Hepatitis A outbreak in Barcelona among men who have sex with men (MSM), January-June 2017: A hospital perspective. Liver Int. 2018;38:588-93.

29. Werber D, Michaelis K, Hausner M, Sissolak D, Wenzel J, Bitzegeio J, et al. Ongoing outbreaks of hepatitis $A$ among men who have sex with men (MSM), Berlin, November 2016 to January 2017 - linked to other German cities and European countries. Euro Surveill. 2017;22:30457.

30. Foster MA, Hofmeister MG, Kupronis BA, Lin Y, Xia GL, Yin S, et al. Increase in hepatitis A virus infections - United States, 2013-2018. MMWR Morb Mortal Wkly Rep. 2019;68:413-5.

31. Latash J, Dorsinville M, Del Rosso P, Antwi M, Reddy V, Waechter $\mathrm{H}$, et al. Notes from the field: increase in reported hepatitis A infections among men who have sex with men — New York City, January-August 2017. MMWR Morb Mortal Wkly Rep. 2017;66:999-1000.
32. Tanaka S, Kishi T, Ishihara A, Watanabe D, Uehira T, Ishida H, et al. Outbreak of hepatitis A linked to European outbreaks among men who have sex with men in Osaka, Japan, from March to July 2018. Hepatol Res. 2019:49:705-10.

33. Takechi A, Hatakeyama S, Kashiyama T, Koibuchi T. Outbreak of hepatitis A virus infection among men who have sex with men. Kansenshogaku Zasshi. 2000;74:716-9.

34. NIID surveillance data. NIID, Tokyo, 2015-2019. https://www.niid.go.jp/ niid/en/. Accessed 24 Jul 2019.

35. Lin KY, Sun HY, Chen YH, Lo YC, Hsieh SM, Sheng WH, et al. Effect of a hepatitis A vaccination campaign during a hepatitis A outbreak in Taiwan, 2015 -2017: a modeling study. Clin Infect Dis. 2019:ciz471.

36. Van Effelterre TP, Zink TK, Hoet BJ, Hausdorff WP, Rosenthal P. A mathematical model of hepatitis a transmission in the United States indicates value of universal childhood immunization. Clin Infect Dis. 2006;43:158-64.

37. Van Effelterre T, Marano C, Jacobsen KH. Modeling the hepatitis A epidemiological transition in Thailand. Vaccine. 2016;34:555-62.

38. Ajelli M, lannelli M, Manfredi P, Ciofi degli Atti ML. Basic mathematical models for the temporal dynamics of HAV in medium-endemicity Italian areas. Vaccine. 2008;26:1697-707.

39. de Guimaraens MA, Codeço CT. Experiments with mathematical models to simulate hepatitis A population dynamics under different levels of endemicity. Cad Saude Publica. 2005;21:1531-9.

40. Jacobsen KH, Koopman JS. The effects of socioeconomic development on worldwide hepatitis A virus seroprevalence patterns. Int J Epidemiol. 2005;34:600-9.

41. Gay NJ. A model of long-term decline in the transmissibility of an infectious disease: implications for the incidence of hepatitis A. Int J Epidemiol. 1996;25:854-61.

42. Hu MD, Schenzle D, Deinhardt F, Scheid R. Epidemiology of hepatitis A and $B$ in the Shanghai area: prevalence of serum markers. Am J Epidemiol. 1984;120:404-13.

43. Regan DG, Wood JG, Benevent C, Ali H, Smith LW, Robertson PW, et al. Estimating the critical immunity threshold for preventing hepatitis A outbreaks in men who have sex with men. Epidemiol Infect. 2016;144:1528-37.

44. Friedman MS, Blake PA, Koehler JE, Hutwagner LC, Toomey KE. Factors influencing a communitywide campaign to administer hepatitis A vaccine to men who have sex with men. Am J Public Health. 2000;90:1942-6.

\section{Publisher's Note}

Springer Nature remains neutral with regard to jurisdictional claims in published maps and institutional affiliations.
Ready to submit your research? Choose BMC and benefit from:

- fast, convenient online submission

- thorough peer review by experienced researchers in your field

- rapid publication on acceptance

- support for research data, including large and complex data types

- gold Open Access which fosters wider collaboration and increased citations

- maximum visibility for your research: over $100 \mathrm{M}$ website views per year

At BMC, research is always in progress.

Learn more biomedcentral.com/submissions 